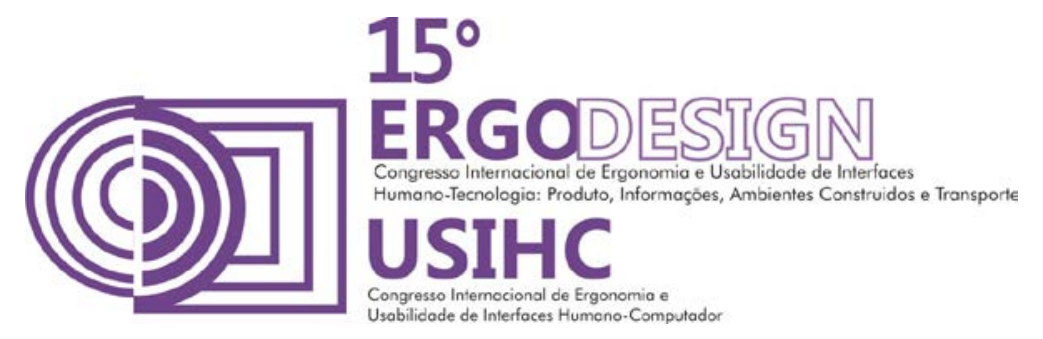

\title{
NECESSIDADES ESPECIAIS E DIFICULDADES DO IDOSO NO AMBIENTE DE SUPERMERCADO: UMA REVISÃO DOS ASPECTOS ERGONÔMICOS
}

\section{NEEDS AND DIFFICULTIES OF THE ELDERLY IN THE SUPERMARKET ENVIRONMENT: A REVIEW OF ERGONOMICS}

\author{
FADIGATTI, Thaylla F. Mazzei (1); \\ RIGOLINO, Marcelo Rolan (2); \\ MEDOLA, Fausto Orsi (3); \\ PASCHOARELLli, Luis Carlos (4).
}

(1) Programa de Pós-graduação em Design FAAC/UNESP - Universidade Estadual Paulista

"Júlio de Mesquita Filho", Bauru, SP.

e-mail: fadigatti-arquitetura@hotmail.com

(2) Programa de Pós-graduação em Design FAAC/UNESP - Universidade Estadual Paulista

"Júlio de Mesquita Filho", Bauru, SP.

e-mail:marcelo.rigolino@gmail.com

(3) Programa de Pós-graduação em Design FAAC/UNESP - Universidade Estadual Paulista

"Júlio de Mesquita Filho", Bauru, SP.

e-mail: fausto.medola@faac.unesp.br

(4) Programa de Pós-graduação em Design FAAC/UNESP - Universidade Estadual Paulista "Júlio de Mesquita Filho", Bauru, SP.

e-mail: paschoarelli@faac.unesp.br

\section{RESUMO}

Em vários países, as populações estão envelhecendo. Este contexto traz ao design desafios e perspectivas inovadoras no que diz respeito aos aspectos de inclusão, acessibilidade e participação social do idoso. Este estudo visa discutir os aspectos ergonômicos e inclusivos do design do ambiente de supermercados, focados no indivíduo idoso. Para isto, foi realizado um estudo de revisão bibliográfico. Esta revisão levou a definição dos problemas, sua relação com os aspectos físicos e cognitivos e possíveis soluções a serem desenvolvidas. Destacam-se três categorias de problemas: Organização e Layout do supermercado; Acesso aos produtos e dispositivos de interface e Leitura de Informações. 


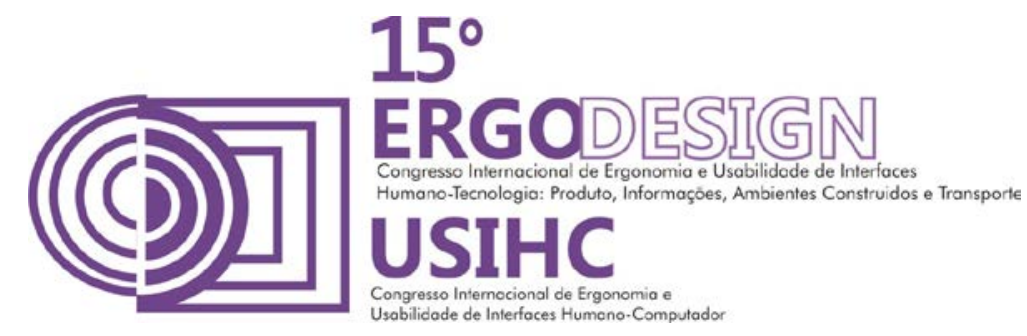

Palavras-chave: Idoso, Supermercado, Ambiente, Design, Ergonomia.

\begin{abstract}
In many countries, populations are aging. This brings challenges to the design and innovative perspectives with regard to the aspects of inclusion, accessibility and social participation of the elderly. This study discusses the aspects of the ergonomics and inclusive environment design of supermarkets, focusing on the elderly. A bibliographic review was conducted and led to the definition of problems, their relationship to the elderly physical and cognitive limitations aspects and possible solutions to be developed. Three categories of problems are highlighted: Supermarket Organization and Layout; access to products and interface devices and reading information.
\end{abstract}

Keywords: Elderly, Supermarket, Environment, Design, Ergonomics.

\title{
1. INTRODUÇÃO
}

Em vários países, as populações estão envelhecendo. Estudos mostram que o número de pessoas idosas cresce em ritmo maior do que o número de pessoas que nascem, acarretando um conjunto de situações que modificam a estrutura de gastos dos países em uma série de áreas importantes. Este novo contexto traz ao design desafios e perspectivas inovadoras ao design, especialmente no que diz respeito aos aspectos de inclusão, acessibilidade e participação social do indivíduo idoso.

No Brasil, o ritmo de crescimento da população idosa tem sido sistemático e consistente. Segundo a Pesquisa Nacional por Amostra de Domicílios - PNAD 2009, o País contava com uma população de cerca de 21 milhões de pessoas de 60 anos ou mais de idade (IBGE, 2010). Segundo dados da ONU (2014), a população com 60 anos ou mais deve triplicar até o ano 2050 fazendo com que a maioria dos países, inclusive o Brasil, adote políticas com relação ao bem estar desta faixa etária.

Segundo a Sociedade Beneficente Israelita Brasileira (2014), com o avançar da idade, o indivíduo torna-se mais frágil, principalmente devido a mudanças inerentes ao próprio processo natural do envelhecimento, como a redução da visão e audição, deformidades músculoesqueléticas, diminuição da massa muscular, de alterações do equilíbrio e da mobilidade e do aparecimento de doenças crônico-degenerativas ao longo do tempo. Todos esses fatores aumentam as dificuldades do idoso nas atividades do dia-a-dia.

Devido as necessidades naturais e diárias de alimentação, o supermercado é um destino natural dos idosos e tem grande importância não só para a manutenção de sua dispensa de alimentos, mas serve também como fonte de lazer e diversão.

Neste sentido, este estudo tem como objetivo discutir os aspectos ergonômicos e inclusivos do design do ambiente de supermercados a partir de uma análise focada no indivíduo idoso. Para isto, foi realizado um estudo de revisão bibliográfica - levantamento de trabalhos científicos diretamente relacionados aos descritores que direcionam o presente estudo: idoso, 


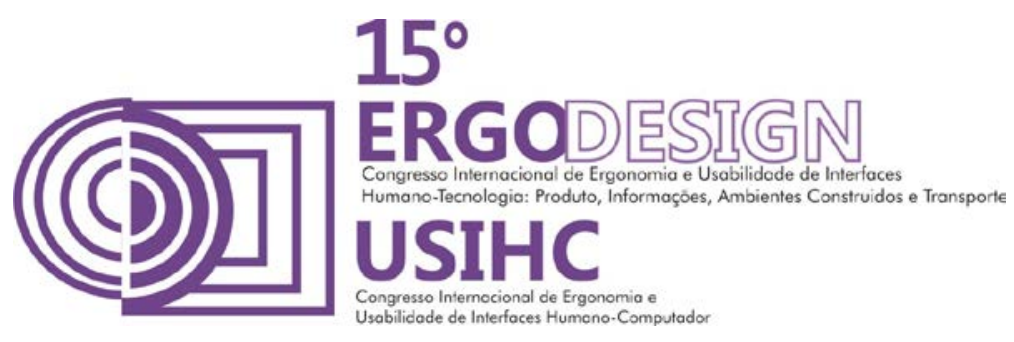

supermercado, design do ambiente, ergonomia e inclusão social. Desta forma, buscou-se compreender os problemas encontrados pelos idosos em supermercados e possíveis soluções propostas.

\section{REVISÃO TEÓRICA}

\subsection{Considerações sobre o processo de Envelhecimento}

Existem diferentes graus de dependência dos idosos, há os que são independentes para fazer todas as suas atividades e possuem grande autonomia, outros que são totalmente dependentes e necessitam de ajuda de outras pessoas (parentes ou cuidadores) e por fim, idosos que dependem de outras pessoas apenas em algumas atividades do seu dia a dia. O grau de dependência do idoso está grandemente relacionado com as mudanças físicas e funcionais que acontecem com o envelhecimento: a estatura das pessoas começa a diminuir gradativamente depois dos 50 anos. Os homens perdem $3 \mathrm{~cm}$ até os 80 anos, e as mulheres, $2,5 \mathrm{~cm}$. Contudo, as maiores influências ocorrem nos dados de antropometria dinâmica. Há redução dos alcances e da flexibilidades, especialmente dos braços. Dessa forma, para o uso de dados antropométricos tabelados, é necessário fazer certas reduções quando se trata de pessoas idosas. A força muscular começa a declinar significativamente após os 40 anos. Para o homem, a força máxima ocorre por volta dos 25 anos (100\%) e ela se reduz a 95\% aos 40, 80\% aos 50 e $50 \%$ aos 60 . Aos 50 anos, as mulheres conseguem exercer aproximadamente a metade da força dos homens de mesma idade. Contudo, esse declínio não ocorre uniformemente em todas as partes do corpo. Os braços e as mãos são menos afetados pela idade do que o tronco e as pernas (IIDA, 2005).

Além dos aspectos físicos decorrentes do envelhecimento, existem também as questões sociais que envolvem a perda de capacidade produtiva e da participação do idoso em atividades sociais. Segundo Camarano (2004): "A ideia do idoso como cidadão improdutivo leva a se pensar que mesmo que o envelhecimento seja desejável sob perspectivas dos indivíduos, 0 crescimento da população idosa pode acarretar em um peso sobre a população jovem e o custo de sustentá-la vir a ser uma ameaça ao futuro das nações. (...) Essa idéia deu origem à preocupação com a 'crise do envelhecimento', pois os idosos são considerados grandes consumidores de recursos públicos, principalmente, de benefícios previdenciário e serviços de saúde. (...) Muito embora essa visão seja pessimista, ela foi importante para a legitimação de alguns direitos sociais, como a universalização da aposentadoria."

Devido a esses fatores limitantes na capacidade física, cognitiva e social dos idosos existe uma discussão sobre a classificação das limitações dos idosos pela organização mundial da saúde, gerando diferentes abordagens sobre a designação para efeito de classificação de suas limitações físicas. O termo deficiente, ainda que outrora algumas vezes tenha sido relacionado aos idosos, não é adequado. Esta denominação foi substituída pela Organização Mundial de Saúde na ICIDH (International Classification of Functioning, Disability and Healt), pelo termo "restrições", para indicar o grau de dificuldade que cada indivíduo possui para realização de uma determinada tarefa (BINSY ELY et al, 2006) 


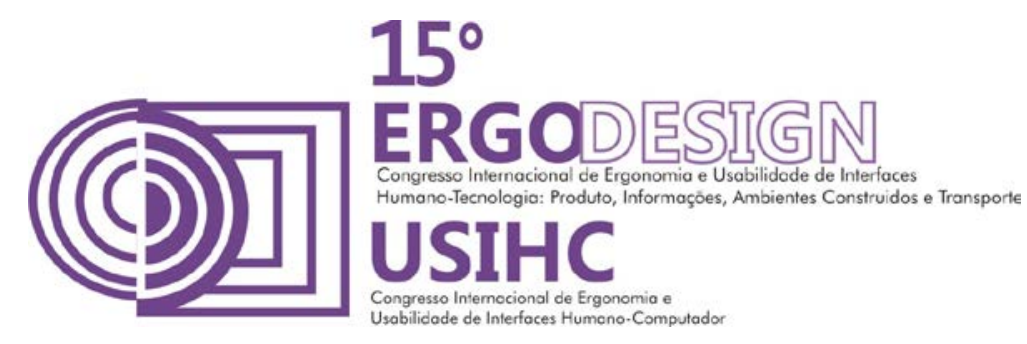

Silva e Motta (2004) afirmam que o comportamento do consumidor idoso é tido como resultado de um processo de envelhecimento e de experiências através do espaço de vida que é diferente para cada indivíduo em virtude da consequência da história e de contextos culturais aos quais os seres humanos estão inseridos. O processo de envelhecimento ocorre de maneira diferente através do espaço de vida e não se pode assumir que pessoas com idades semelhantes possam dividir as mesmas experiências ou tenham o mesmo processo de envelhecimento.

O envelhecimento biológico pode requerer do idoso uma série de cuidados: preferência por alimentos dietéticos, se o idoso for diabético, o uso de fraldas descartáveis para incontinência urinária e roupas apropriadas para idade, visto que o corpo se modifica com o avanço da idade.

No caso do envelhecimento psicológico, o processo pode estar relacionado à busca de informações e as habilidades em resolver problemas, tais como lembrança, compreensão, avaliação e retenção. Estes problemas são influenciados pelo envelhecimento biológico e por fatores psicológicos, como por exemplo, a saúde mental.

Os fatores socioculturais e ambientais também influenciam no envelhecimento psicológico. Com isso, a empresa pode definir segmentos de mercado com base na idade cognitiva do indivíduo, ao invés da sua idade cronológica e então desenvolver apelos de comunicação sem precisar lidar diretamente com a aceitação e rejeição psicológica da idade cronológica do consumidor (Silva e Motta, 2004).

O envelhecimento sociológico pode ser identificado no caso do consumidor assumir novos papéis com o seu amadurecimento biológico e psicológico, tendendo a redefinir sua prioridade e necessidades de consumo. Assim sendo, a empresa pode se beneficiar da compreensão dos estágios de transição dos indivíduos, segmentando melhor o seu mercado, podendo posicionar produtos e serviços com o objetivo de facilitar a adaptação dos novos papéis desses consumidores (Silva e Motta, 2004).

A rápida evolução no campo da medicina, tecnologias assistivas. Programas sociais e culturais, estão mudando rapidamente o perfil da população idosa no mundo todo, os chamados novos idosos participantes do "envelhecimento ativo". Este termo foi adotado pela Organização Mundial da Saúde no final dos anos 90, e procura transmitir uma mensagem mais abrangente do que "envelhecimento saudável", e reconhecer, além dos cuidados com a saúde, outros fatores que afetam o modo como os indivíduos e as populações envelhecem (Kalache e Kickbusch, 1997).

A terceira idade foi tradicionalmente associada à aposentadoria, doença e dependência. As políticas e programas vinculadas a este paradigma ultrapassado não refletem a realidade pois, na verdade, a maioria das pessoas permanece independente na idade mais avançada.

Especialmente nos países em desenvolvimento, várias pessoas acima de 60 anos continuam a participar da força de trabalho. Os indivíduos idosos são ativos no setor de trabalho informal (por exemplo, trabalho doméstico e atividades autônomas, de pequena escala) embora isto não 


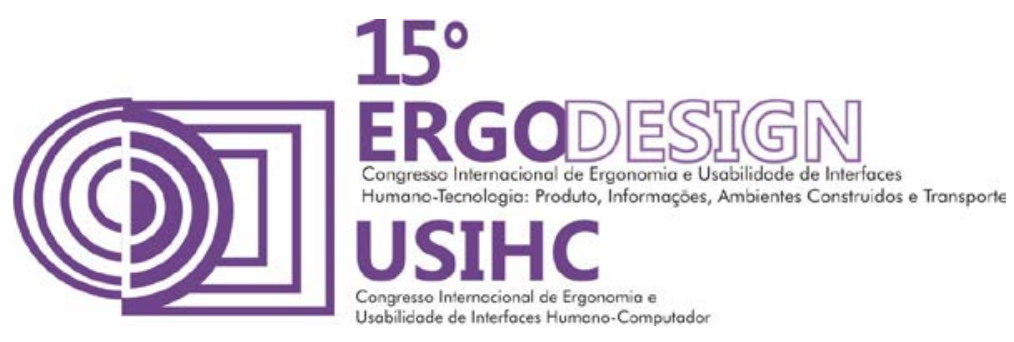

seja reconhecido nas estatísticas do mercado de trabalho.

A contribuição não remunerada das pessoas idosas em casa (tais como tomar conta de crianças ou de pessoas doentes) permite que os jovens da família tenham atividades remuneradas. Em todos os países, as atividades voluntárias dos idosos são uma importante contribuição social e econômica para a sociedade. (OPS, 2005)

\subsection{Aspectos ergonômicos do ambiente de supermercado}

Os estudos e pesquisas em Ergonomia, Antropometria e Tecnologias Assistivas, tem tido um papel relevante na melhoria das condições de uso de produtos e espaços públicos.

Ao observarmos o ambiente do supermercado, podemos verificar alguns problemas, como prateleiras muito altas ou muito baixas, piso escorregadio, falta de sinalização, placas pouco contrastantes, quando há, placas ilegíveis e preços dispostos de forma confusa ou pouco legíveis.

Como parte das estratégias de vendas dos supermercados, a mudança constante de produtos em suas prateleiras é uma prática que busca fazer com que o consumidor percorra seus corredores e consequentemente tenha acesso a um maior número de produtos e marcas, aumentando assim o potencial de vendas desses produtos.

Essa prática no entanto acaba por modificar a organização do supermercado, fazendo com que os idosos, principalmente, se percam e tenham que percorrer caminhos mais longos em busca dos produtos de sua lista de compra. Esses problemas podem ser classificados então em três categorias: organização e layout do supermercado; acessibilidade dos produtos nas prateleiras e dos dispositivos de interface (leitores de código de barras, caixas); Leitura de Informações sobre produtos e preços.

\subsection{O idoso no supermercado: desafios e perspectivas para a acessibilidade}

Os idosos vão ao supermercado ao menos uma vez por semana, consideram o ato de ir às compras uma atividade de lazer e gostam de pagar à vista, em dinheiro. E mais: injetam R\$ 150 milhões por ano na economia brasileira, conforme pesquisa da consultoria GFK Indicator (2008). Ainda assim, os consumidores de terceira idade parecem passar despercebidos aos olhos das redes de varejo, que não traçam uma estratégia diferenciada para atrair este público.

Com o objetivo de conhecê-los melhor, o Programa de Administração de Varejo (Provar) da Fundação Instituto de Administração (FIA) e a Canal Varejo acabam de concluir a pesquisa Perfil e Hábitos de Consumo na Terceira Idade, que ouviu 250 paulistanos de mais de 60 anos de 5 regiões da cidade. O estudo, segundo o coordenador geral do Provar, Claudio Felisoni, reflete um comportamento nacional. Um dos pontos que chamaram a atenção foi o fato de mais da metade (54\%) dos entrevistados admitir experimentar novas marcas, desmentindo a crença de que o consumidor idoso é conservador. Grande parte (20\%), segundo a pesquisa, associa as compras a uma atividade de lazer. 


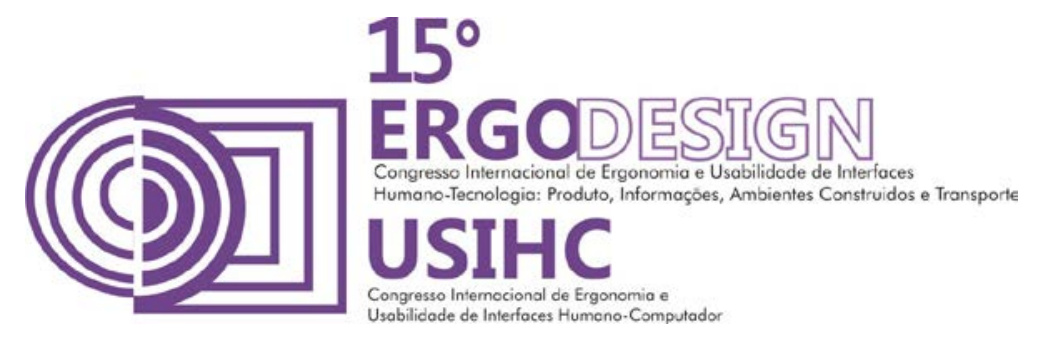

Quando questionados sobre a frequência com que, costumeiramente, vão aos supermercados, $28,4 \%$ relatou ter este hábito diariamente, outros $39,4 \%$ dos entrevistados responderam ser semanalmente. Cabe destacar que $12,8 \%$ do público pesquisado manifestaram preferência por realizar suas compras apenas nos finais de semana.

A pesquisa também permitiu compreender os motivos que levam os idosos aos supermercados. O Bom atendimento destacou-se com 35,8\% das respostas. Na sequência, com 24,8\%, destacou-se o Preço como o segundo motivo. Por sua vez, 15,6\% dos idosos relataram que vão ao supermercado a Lazer e passeio. Com este mesmo percentual apareceu que a boa localização também faz com que o idoso vá ao supermercado (LONDRES, 2006).

Esses dados e informações mostram a relevância do estudo de novas maneiras de projetar os espaços destinados a compras e, mais especificamente os supermercados, com foco no público idoso. Tendo como ponto de partida as características limitantes atribuídas aos idosos, nas três categorias destacadas acima, pudemos verificar algumas iniciativas publicadas em periódicos da área do comercio de supermercados e em artigos científicos com a finalidade de propor soluções a estes problemas e até já adotadas em estabelecimentos.

\section{CONHECA INICIATIVAS DA ALEMA KAISER'S NO ATENDIMENTO A CLIENTES DE MAIS IDADE}

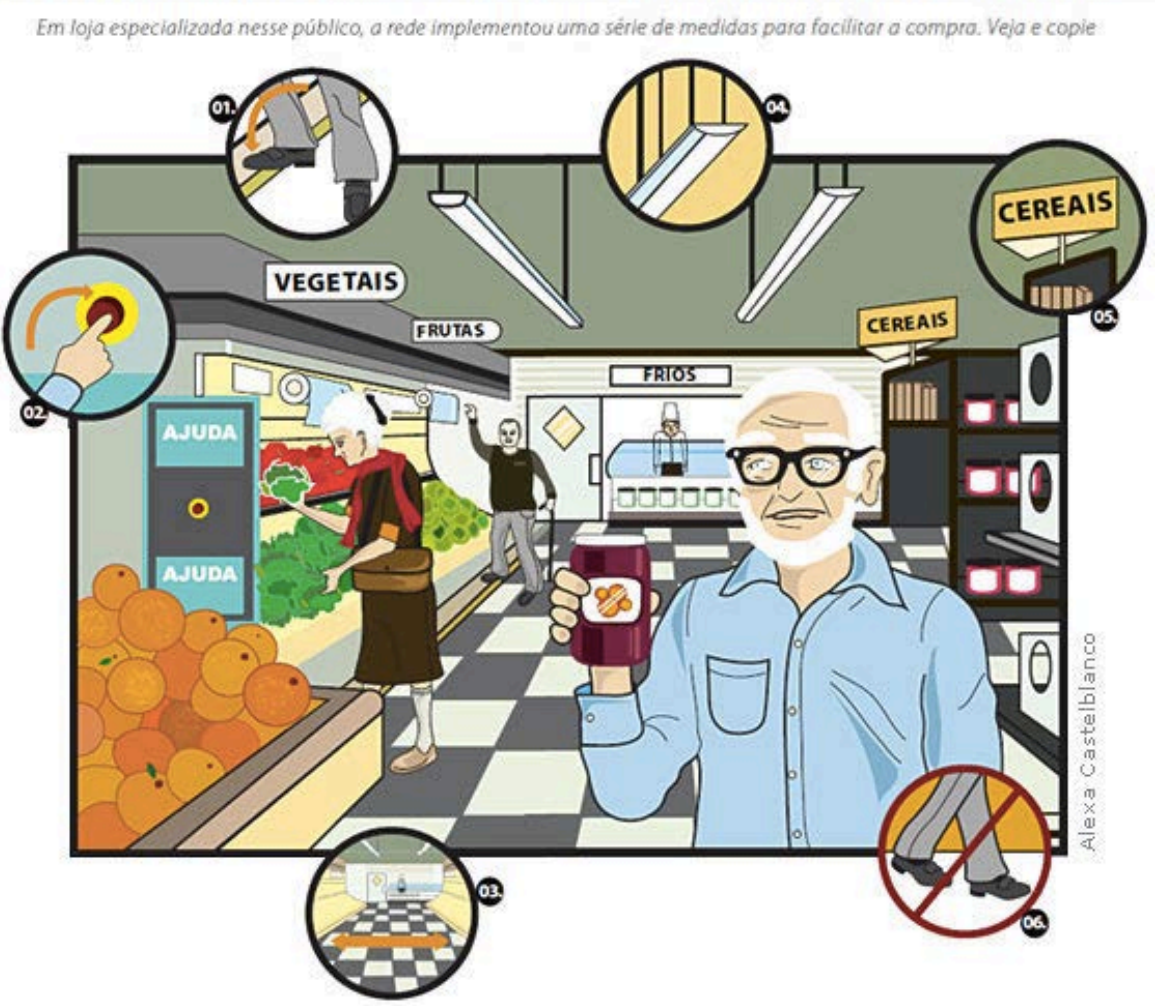

Fonte: http://www.sm.com.br/Editorias/Negocios/Lojas-ao-alcance-deles-22087.html?index=2 


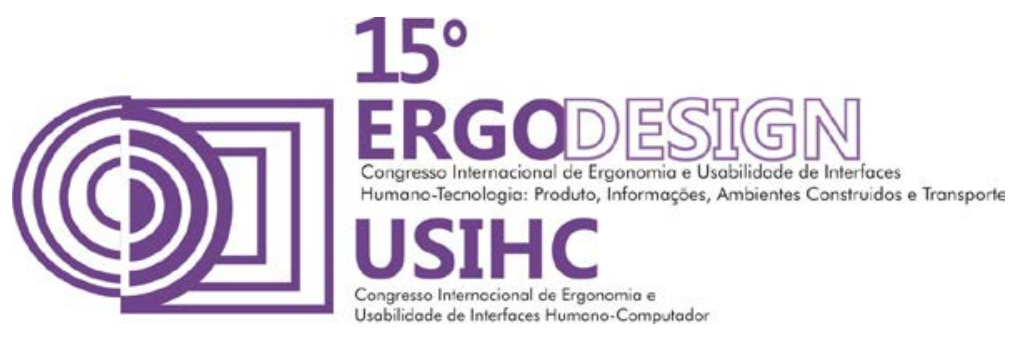

\section{1 - Degrau embutido}

Como é difícil colocar gôndolas mais baixas em algumas seções, a Kaiser's instalou degraus para o idoso alcançar os produtos expostos no alto

\section{2 - Botão de ajuda}

Botões vermelhos espalhados por toda a loja podem ser acionados pelos clientes a qualquer momento para solicitar a ajuda de um funcionário

\section{3 - Corredores largos}

Devido à dificuldade de mobilidade dos mais velhos, a Kaiser's optou por corredores largos para evitar trombadas de carrinhos e outras situações nas quais existam risco de machucar braços ou pernas

\section{4 - Luzes claras}

A filial da Kaiser's é bem iluminada. Além de facilitar a visão dos produtos nas prateleiras, o idoso fica mais calmo, pois enxerga por onde está caminhando

\section{5 - Sinalização grande}

Com o avanço da idade, as pessoas têm maior dificuldade para ler. Por isso, toda a sinalização da loja, inclusive das seções, é feita com letras grandes luminosas

\section{6 - Piso antiderrapante}

A queda é um evento bastante comum entre idosos e pode ter consequências graves. Por isso, para evitar acidentes, a opção da loja foi adotar piso antiderrapante sintético (SILVESTRINI, 2013)

O layout precisa ser apresentado de forma clara, breve, precisa, organizada, agradável e eficiente ao consumidor, estimulando a compra. Algumas cores são associadas a certas repartições como o verde às frutas e legumes. Tais aspectos auxiliam de forma intuitiva no momento da compra, sem que o consumidor precise parar para ler o que está escrito. Outra forma de reforçar a localização de um produto é o uso de imagens de produtos representativos de sua categoria.

As placas geralmente ficam no alto para facilitar a identificação. Alguns supermercados revestem os pisos utilizando cores para identificar sessões, como por exemplo o piso revestido de vermelho para identificar o açougue. Outros proprietários acreditam que isto limitaria possíveis mudanças de setores. O que poderia ser utilizado no piso são fitas adesivas coloridas, que são de fácil remoção.

Do ponto de vista ergonômico, seria importante que uma determinada técnica fosse utilizada em diversos estabelecimentos, para que o consumidor possa ir em qualquer supermercado e encontrar os produtos com facilidade. Para isto, é importante que novos estudos investiguem quais aspectos do design do ambiente e informação em um supermercado contribui para a melhor interação do idoso. 


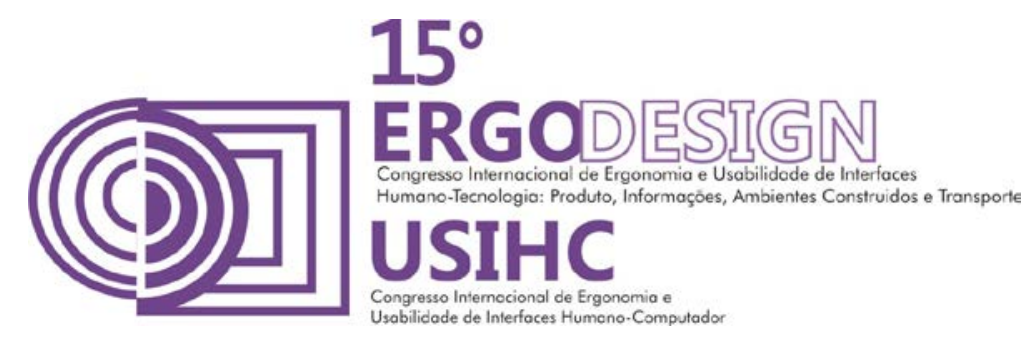

Outra circunstância inconveniente para os idosos na hora da compra é o excesso de informação disposta por todo o ambiente do supermercado: cartazes de oferta, placas indicando as sessões, entre outros. No entanto, nem sempre estas placas facilitam a vida do consumidor, e podem mesmo gerar desconforto visual. As placas devem estar localizadas de forma adequada para que o consumidor possa se orientar através delas. O que ocorre é que, muitas vezes, o consumidor acaba não prestando atenção nos dizeres das placas devido a confusão de informações, gastando mais tempo para localização dos produtos que necessita, sendo comum acabar levando o que não precisa esquecendo suas reais necessidades de compra.

O Layout tem que apresentar vantagens tanto para o consumidor quanto para os varejistas. Para o consumidor o layout auxiliaria nas compras, economizando tempo e lembrando das suas necessidades, pois muitas vezes o consumidor não possui tempo disponível para percorrer todo o supermercado afim de encontrar seu produto. Em alguns supermercados usa-se a técnica de modificar semanalmente a colocação dos produtos em diferentes prateleiras e corredores, para que o cliente gaste mais tempo dentro do supermercado e, desta forma, compre mais. Essa modificação pode dificultar a localização para a maioria das pessoas, especialmente para 0 idoso. Neste sentido, os proprietários devem entender que o que a princípio possa parecer uma vantagem, a dificuldade na localização do produto pode implicar em insatisfação do cliente. Para o varejista, um layout bem elaborado atrai novos consumidores e gera fidelidade.

\section{CONSIDERAÇÕES FINAIS.}

O presente estudo destacou a importância de se considerar os aspectos ergonômicos e inclusivos do idoso no design de ambientes de supermercado. Apesar da evidente relevância do tema, de acordo com nosso conhecimento até o presente momento foi encontrado apenas um estudo que tenha abordado diretamente as dificuldades do idoso no supermercado, o que reflete a necessidade de se realizar pesquisas aplicadas afim de se conhecer quais aspectos do design do ambiente de supermercado estão mais diretamente relacionados à inclusão, segurança, independência e satisfação do indivíduo idoso em sua interação no processo de compra.

Os estudos analisados abordam claramente os aspectos limitantes dos espaços dos supermercados para uso de idosos e de pessoas com necessidades especiais, permitindo-se verificar também inúmeras iniciativas em busca de diretrizes para solucionar os problemas e alguns casos de soluções já adotadas por estabelecimentos.

Apesar de serem evidentes as necessidades de avanços na organização, comunicação visual, layout e ergonomia dos supermercados para atender a uma variedade de necessidades especiais, especialmente ao público idoso, os designers e estudiosos deste assunto devem discutir também alguns aspectos da definição de Idoso como temos hoje e do novo idoso que teremos daqui a poucos anos.

Os estudos mostram inúmeras necessidades de melhorias dos ambientes compartilhados por idosos sejam eles nos supermercados, farmácias ou espaços públicos. Assim, fica evidente que muitos desses problemas são comuns também ao público jovem, apenas agravados nos 


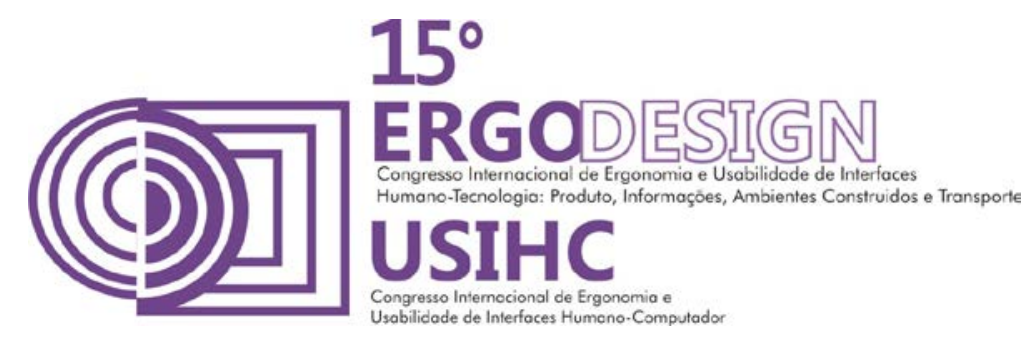

idosos, muito em parte devido às capacidades limitantes que a idade os atribui. Desta forma os as propostas de solução para os problemas encontrados nos supermercados e espaços públicos será de utilidade ainda mais ampla.

\section{REFERÊNCIAS BIBLIOGRÁFICAS}

BINS ELY, Vera H.M; et. Al. Jardim Universal - Espaço Livre Público para Todos. Curitiba: Anais Abergo, 2006.

CAMARANO, Ana Amélia. Os novos idosos brasileiros, muito além dos 60. Rio de Janeiro: IPEA Instituto de Pesquisa Económica Aplicada, 2004. 604p.

COOK, A. M.; HUSSEY, S. M. Assistive Technologies: Principles and Practices. St. Louis, Missouri. Mosby - Year Book, Inc, 1995.

IBGE. Síntese de Indicadores Sociais: Uma Análise das Condições de Vida da População Brasileira: 2010, p. 191. Disponível em: http://teen.ibge.gov.br/mao-na-roda/idosos Acesso em: 30 Novembro 2014.

IIDA, Itiro. Ergonomia: projeto e produção. Editora: Edgard Blucher, São Paulo, 2000, pag; 465.

KALACHE, A., KICKBUSCH, I. A global strategy for healthy ageing. World Health, n. 4, p. 4-5, 1997.

LONDRES. Mariana. Idosos gostam de comprar e vão com frequência ao supermercado. Gazeta Do Povo, 2006. Disponível em http://www.gazetadopovo.com.br/economia/conteudo.phtml?id=567878 Acesso em: 30 Novembro 2014.

PANERO, Julius; ZELNIK, Martin. Dimensionamento humano para espaços interiores: um livro de consulta e referência para projetos. Editora GG, Barcelona, 2002-2005, pag; 320.

SILVA, H.S; MOTTA, V.L.B. Terceira Idade: Diferencial Competitivo Numa Empresa. Revista Eletrônica ISSN 1677- $4280-$ Volume $3-2004 /$ número 1 . Disponível em http://revista.uepb.edu.br/index.php/qualitas/article/viewFile/33/25 Acesso em: 04 Janeiro 2015.

SILVESTRINI, A. lojas ao alcance deles. 2013. Disponível em : http://www.sm.com.br/Editorias/Negocios/Lojas-ao-alcance-deles-22087.html?index=2 Acesso em: 27 Dezembro 2014.

SOCIEDADE BENEFICENTE ISRAELITA BRASILEIRA. Bem estar e Qualidade de Vida. 2012. Disponível em: <http://www.einstein.br/einstein-saude/bem-estar-e-qualidade-de-vida/Paginas/comoprevenir-a-queda-de-idosos.aspx>. Acesso em: 11 setembro 2014.

ONU BR - Nações Unidos no Brasil. A ONU e as pessoas idosas. Disponível em: <http://www.onu.org.br/a-onu-em-acao/a-onu-em-acao/a-onu-e-as-pessoas-idosas/>. Acesso em: 16 agosto 2014. 